\title{
Agenda Setting Trends: Twitter Topic Trending For Online News Sites In The 2019 Presidential Election
}

\author{
Yudid Andri ${ }^{1}$, Suraya ${ }^{2}$ \\ \{yudid.andri@gmail.com ${ }^{1}$, suraya.suraya@mercubuana.ac.id² \\ Universitas Mercu Buana, Jakarta, Indonesia ${ }^{12}$
}

\begin{abstract}
The development of technology in the mass media industry has developed very rapidly both in quantity and quality. Various forms of media that have developed have created a serious debate about the agenda in the public discussion in general in society and the role of mass media in contributing to social problems. The use of computer technology and information systems has created new media such as online media (.com) and social media, which in turn creates its own audience and the interaction within cyberspace. Editorial decisions have experience shift on the content provided on cyber news, from news agenda into public agenda. This research will examine mutual relationship of agenda setting within digital mainstream media, namely the online news site JPNN.com and RMOL.id, with the hashtag trending topic on Twitter during the 2019 presidential election period between 20-26 May 2019. Hypothesis expected in this research that there is a positive mutual relationship between JPNN.com's online media headlines and RMOL.id towards trending topic and hashtags on Twitter. But, the results of the study cannot prove the hypothesis that there is a positive mutual relationship between news agenda of online news sites and public agenda whose using Twitter. The two online news sites have not yet made Twitter as the main reference source for news, as Twitter and other social media are mostly used as media to promote news links and their web portal.
\end{abstract}

Keywords: Agenda Setting; Online Media; Twitter; Presidential Election

\section{Introduction}

Utilization of technology and information systems has created new media such as online media (.com) and social media which have created a unique audience, in recent years the expansion of popular interest in computers as communication media in parallel creates their own audiences [1] [2]. In the end, the computer created the term cybermedia, which was not just a new form of media technology but also created a group of separated and unique audience. One of the characteristics of the new audience was interaction in cyberspace, in a converged contemporary media environment, agenda setting experienced a rapid growth of audiences as media users as well as media producers. Research conducted by Maxwell McCombs and Donald Shaw published in 1972 with the title "The Agenda Setting Function of Mass Media" conveys a view of the influence of the mass media news agenda on the audiences who consume it. These influences include what audiences talk about and audience evaluations of what issues are important to talk about [3]. News produced by the media and the interests or needs of the public have a fairly close relationship to the editor's decision. Understanding the agenda setting according to Chaffee \& Metzger [4], has undergone a shift, 
they indicate that the current phenomenon is not about what issues the media will convey to the public, but rather how the audience will think about the media.

Previous research on intermedia agenda setting in examining the phenomenon of the influence of social media on mainstream media agendas, such as, newspapers and television, not only on Twitter, but also on social media or other internet media, such as, Facebook and Blogs [5]-[7]. Some researchers seize the moment of the election to find out whether the agenda of the presidential candidates presented in his campaign adverts affected the agenda in the social media community [8], [9]. In addition to the intermedia election, social media setting agenda, and on social issues, such as, natural disasters, sports events, and other social agendas [10], [11]. This research will examine the intermedia relationship agenda setting between the digital media, the online news site JPNN.com and RMOL.id, and the trending topic and hashtags on Twitter during the 2019 presidential election, 20-26 May 2019.

\section{Research Method}

This research will use a quantitative research approach with a positivistic paradigm, and content analysis quantitative. The unit of analysis of this research is the headlines from two online media sites namely RMOL.id and JPNN.com and the hashtags on Twitter social media trending topics during the period of 20 May - 26 May 2019. The sample of this research is the headline on the main page of two online media sites, namely RMOL.id and JPNN.com. The units analyzed on the online news website are limited to certain conditions including: (1) News that chosen is only news on the first page of the main slide, sub slides and slides below, (2) Regional news is not part of the sampling unless it has a value of national news, (3) News that are magazine or feature also not included in the sampling. Hashtags on the Twitter social media trending topic taken from the website www.trendinalia.com.

The data generated were analyzed using cross-lagged panels and the Rozelle-Campbell baseline. Cross-lagged panel correlation methods are mostly used in agenda setting research [12]-[17]. Cross correlation is a method for measuring the proposed effect between two variables through the separation of variables with the appropriate amount of time duration. Therefore, with the time allocated between variables, it is suggested that variable 1 will have a proposed effect on variable 2 [18]. This model has six correlations in total consisting of two pairs of three different sets of correlations [18].

Time 1

Time 2

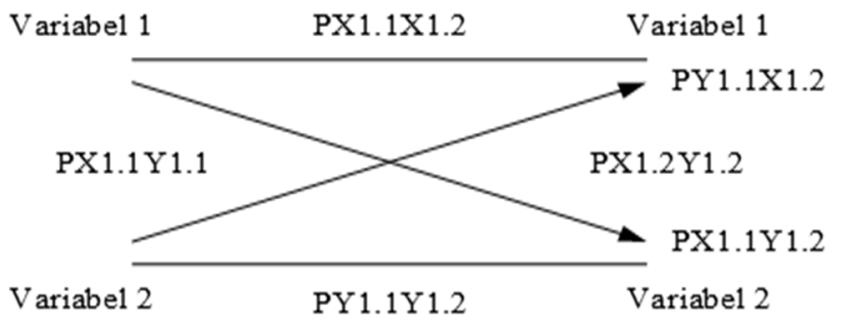

Variable 1: Online Media

Variable 2: Twitter

X1.1: Online Media in the first time (Time 1)

$\mathrm{X} 1.2$ : Online Media in the second time (Time 2) 
Y1.1: Twitter in the first time (Time 1)

Y1.2: Twitter in the second time (Time 2)

The first set of two paired correlations is autocorrelation, which is a correlation between the same variable over time (PX1.1X1.2 and PY1.1Y1.2). The second set of correlations is synchronous correlation, which is the correlation between two variables simultaneously (PX1.1Y1.1 and PX1.2Y1.2). The third and final is cross-lagged correlation. This correlation measures the effect between two different variables at two different times (PX1Y2 and PY1X2) [18]. Two important correlations here are cross correlations between variable 1 (RMOL.id \& JPNN.com), causes, and variable 2 (Twitter) at different times (PX1.1Y1.2) then variable 2 (Twitter), causes, and variable 1 (RMOL.id \& JPNN.com), effects (PY1.1X1.2) because they show the level of influence between the two variables [18].

In the interagency agenda setting study, there have been several modifications made to the original cross-correlation model which is an implementation of the Rozelle-Campbell baseline[12]-[14], [16], [17]. Rozelle and Campbell (1969) [19] designed this baseline to overcome potential weaknesses in the cross correlation model. Baselines are calculated through a formula that considers synchronous correlation and autocorrelation into consideration and determines the threshold below that, even statistically significant crosscorrelations will show no effect [14], [16], [17].

$[(\mathrm{PX} 1.1 \mathrm{Y} 1.1+\mathrm{PX} 1.2 \mathrm{Y} 1.2) / 2]\{[(\mathrm{PX} 1.1 \mathrm{X} 1.2) 2+(\mathrm{PY} 1.1 \mathrm{Y} 1.2) 2] / 2\} 1 / 2$

In order to conclude that there is an effect of setting the media agenda from one media to another, the autocorrelation of the effect variable must be below the baseline statistics, while the cross correlation of the causal variable to the effect variable is above the baseline.

\section{Results and Discussion}

\subsection{Result}

From the results on the frequency that most appear in the media JPNN.com, RMOL.id and Twitter is politics, it is understandable given that the time of data collection coincides with the announcement schedule of the 2019 Presidential Election results. The top three of the most popular themes in the online media JPNN.com are political $(\mathrm{N}=364)$, second is sports $(\mathrm{N}=$ 136), and third is economic $(\mathrm{N}=76)$. On the JPNN.com, the political theme received a significant portion of the news, it can be seen on the 2 nd day of the evening, May 21, 2019, one day before the presidential election announcement, the number of political news trends increased $(\mathrm{N}=54)$. News about the riots against electoral fraud and issues regarding dispute over election results dominated political news on JPNN.com. Then on the 3rd day morning, May 22, 2019, presidential election announcement raises the number of news posted $(\mathrm{N}=59)$.

For sports, national and international football on day $2(\mathrm{~N}=15)$ where League 1 national teams are competing. Then on the 6 th day of the evening $(\mathrm{N}=13)$ and the 7 th day of the morning $(\mathrm{N}=13)$ and evening $(\mathrm{N}=17)$ of Saturday and Sunday, as national soccer competition and European soccer competition happened. The economic news was dominated by the month of Ramadan and preparation for Eid-ul-Fitr holidays. The highest number of news stories on day $2(\mathrm{~N}=13)$ and $3(\mathrm{~N}=10)$ may also be related to political issues, which discussed in relation to economic achievements or infrastructure problems by the government at this time. And the most on the 7 th day $(\mathrm{N}=15)$ due to approaching Eid-ul-Fitr, site was dominated with holiday allowance and readiness of homecoming transportation. 
The top three of the most popular themes in the online media of RMOL.id are political themes $(\mathrm{N}=326)$, then the second highest theme is economic $(\mathrm{N}=27)$, the third is an international theme $(\mathrm{N}=20)$. Political themes also received a significant portion, which can be seen on the second day of the evening, May 21, 2019, one day before the presidential election announcement, number of political news trends also appears to be increasing $(N=37)$. Similar to the online media JPNN.com, news about riots on alleged election fraud, also vote recapitulation and the preparations to deal with election disputes. Then on the 3rd day of the morning, May 22, 2019 the number of political news declined slightly in the morning $(\mathrm{N}=26)$ and evening $(\mathrm{N}=36)$, in the morning news, RMOL.id wrote about riots and clashes between the authorities and the demonstrators. In the evening news, RMOL.id wrote about riots' appeal and issues the public to be calm. Regarding the economic theme, on the first day of the morning $(\mathrm{N}=4)$ and evening $(\mathrm{N}=4)$ RMOL.id wrote international issues such as trade wars and oil industry. While the most of economic news was on the 5th day morning $(\mathrm{N}=6)$, RMOL.id covered social activities during the month of Ramadan. For international theme was on day 1, RMOL.id wrote regarding the speech of Pope Francis, and several international warships leaning on Indonesia's water.

The top three of the popular themes on Twitter are political $(\mathrm{N}=67)$, second is entertainment $(\mathrm{N}=64)$, and third is a socio-cultural $(\mathrm{N}=41)$. Just like the two online media, political themes on Twitter trending topics are in the morning of the 2 nd day $(\mathrm{N}=11)$ to the 3rd day $(\mathrm{N}=11)$, which filled with hashtags regarding presidential elections, both of congratulations and criticism. Besides that, the hashtag regarding the riots was also making into trending topic. The entertainment themes were on the 4th day of the evening $(\mathrm{N}=12)$ and the 5th day of the morning $(\mathrm{N}=11)$, regarding KPOP-artists and the death of ustdaz Arifin Ilham. The third is socio-cultural themes, as the most frequent hashtags regarding Ramadhan. The tendency of agenda setting in both directions is shown by the value of the cross correlation and in the same direction of the two media that are counted between days for 7 days of the sampling period.

Day 1 and Day 2

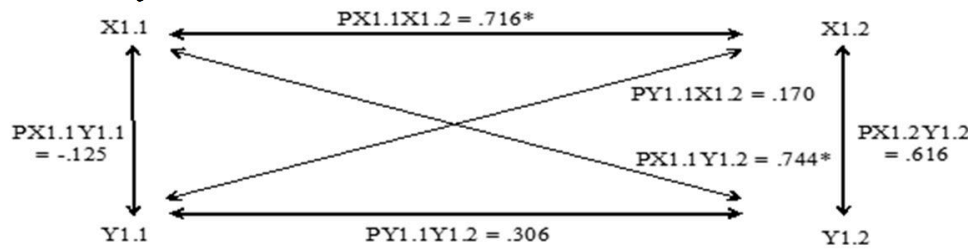

Rozelle-Campbel Baseline $=.135$

Day 2 and Day 3

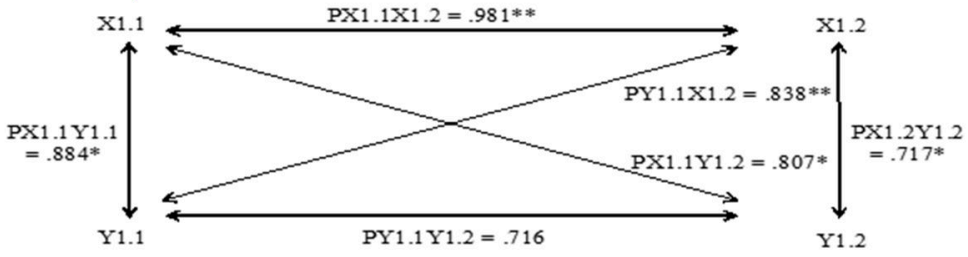

Rozelle-Campbel Baseline $=.687$ 
Day 3 and Day 4

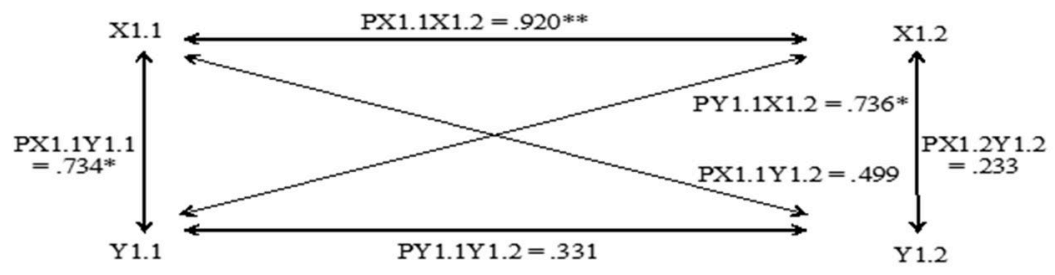

Rozelle-Campbel Baseline $=.334$

Day 4 and Day 5

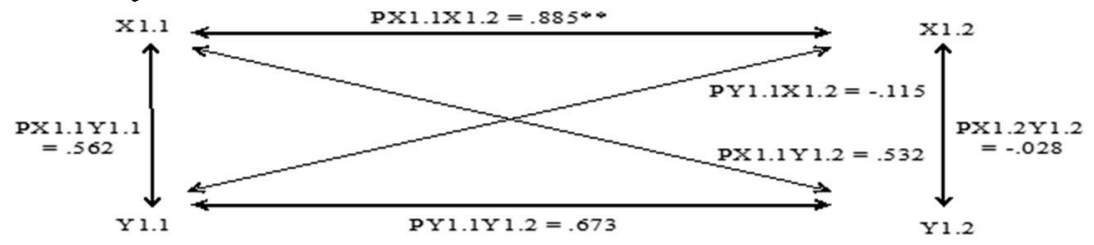

Rozelle-Campbel Baseline $=.209$

Day 5 and Day 6

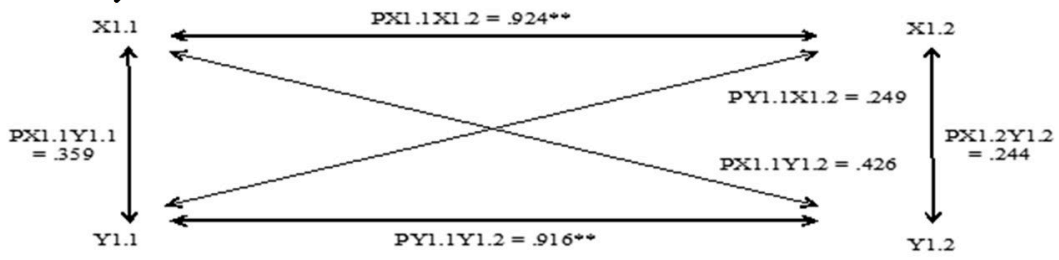

Rozelle-Campbel Baseline $=.277$

Day 6 and Day 7

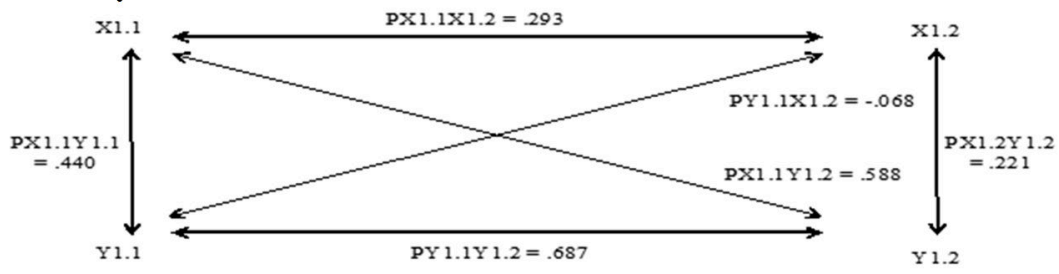

Rozelle-Campbel Baseline $=.297$

Fig 2. Cross-Lagged Correlation between JPNN.com and Twitter between days.

From 6 days inter-day panels, the results found for JPNN.com are there was only 1 panel that methodologically show a mutual agenda setting between the media, namely on day 3 and to day 4. The statistical counts showed that JPNN media affects Twitter media agenda with cross-correlation values $(\mathrm{r}=.499, \mathrm{p}<.01)$ and direct correlation values $(\mathrm{r}=.331, \mathrm{p}<.01)$ below the statistical boundary line (.334) even though the coefficient above the boundary line but the effect is weak. While the significant correlation value from JPNN.com to Twitter is found on day 1-2, day 2-3. While a fairly strong correlation of Twitter on JPNN.com is found on day $2-3$, day 3-4, reverse agenda setting cannot be proven statistically. Thus, it was concluded that the hypothesis proposed in this study whether there was a reciprocal 
relationship between the agenda setting between JPNN.com and Twitter during 6 days of sampling did not occur or there was no influence of the interrelationship between the media.

Day 1 and Day 2

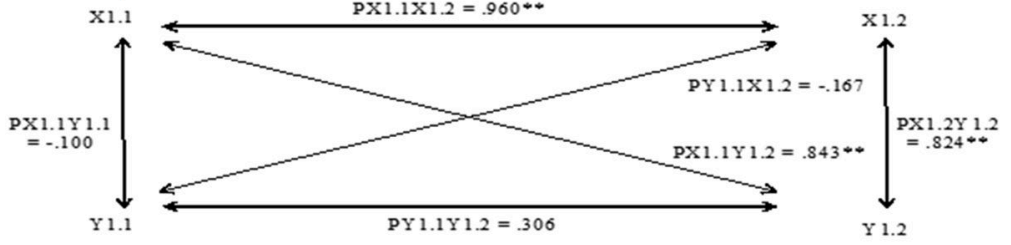

Rozelle-Campbel Baseline $=.257$

Day 2 and Day 3

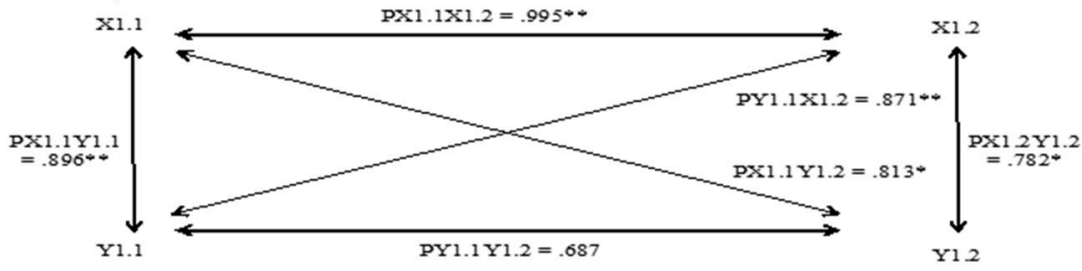

Rozelle-Campbel Baseline $=.727$

Day 3 and Day 4

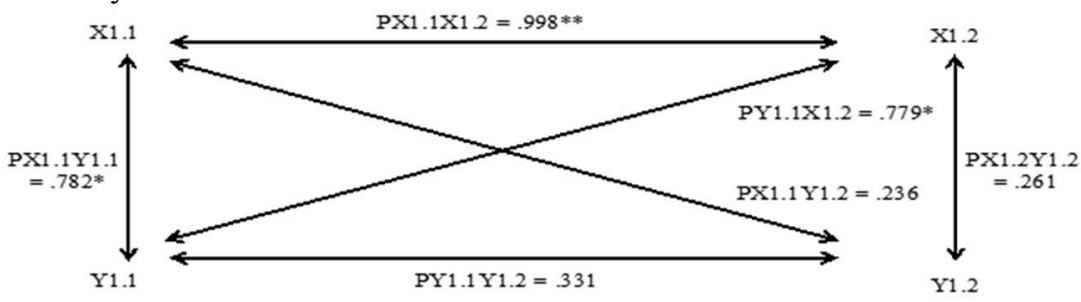

Rozelle-Campbel Baseline $=.387$

Day 4 and Day 5

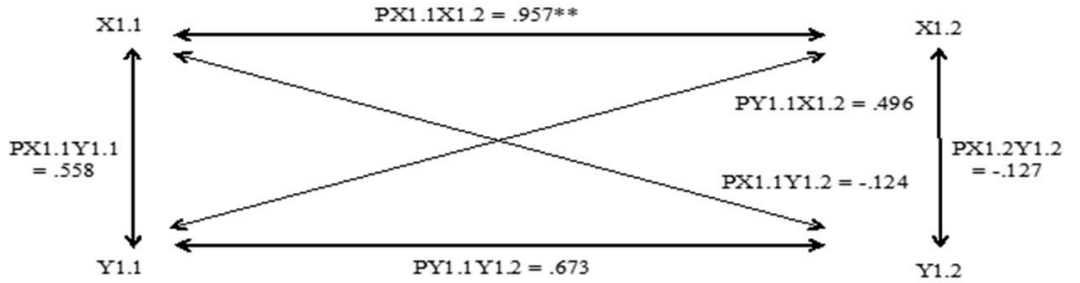

Rozelle-Campbel Baseline $=.178$ 
Day 5 and Day 6

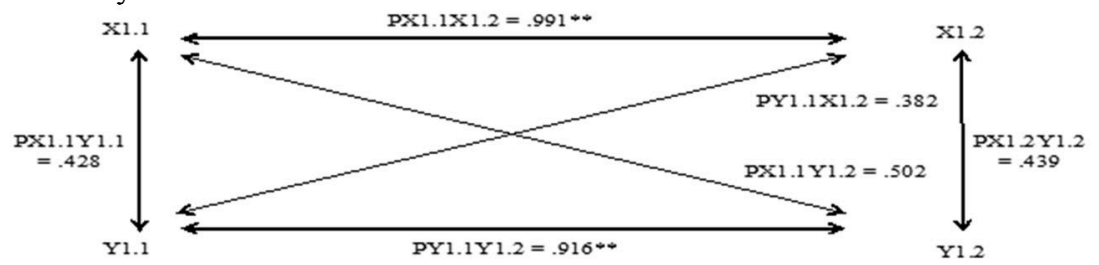

Rozelle-Campbel Baseline $=.413$

Day 6 and Day

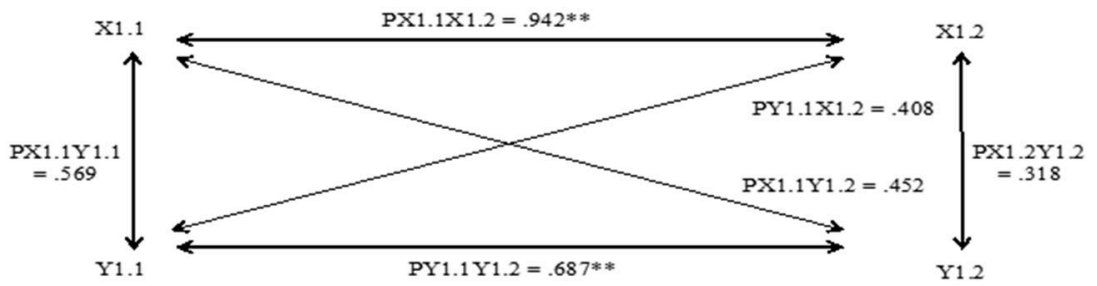

Rozelle-Campbel Baseline $=.365$

As results for RMOL.id, there is only 1 panel which methodologically shown mutual agenda setting between the media, that is on day 2 to day 3 . The statistical count shows that the media RMOL.id influence the media agenda on Twitter with the value of cross-correlation $(\mathrm{r}=.813, \mathrm{p}<.01)$ and the value of direct correlation $(\mathrm{r}=.716, \mathrm{p}<.01)$ below the line of the statistical limit (.727) of the correlation coefficient shows a strong influence relationship, while the significant correlation value from RMOL.id to Twitter was found on days 1 and 2, and the correlation that was quite strong from Twitter to RMOL.id was found on day 2 to day 3 , day 3 to day 4. However, to judge whether reverse agenda setting cannot be proven statistically. Thus, it was concluded that the hypothesis proposed in this study for 6 sampling times did not occur or there was no influence of the interrelationship between the media.

The results of interviews found that social media influenced journalistic work and viewed social media to have an important role in the flow of information. JPPN use Twitter to bounce news in means of share links. JPNN also applied SEO with eye-catching title in accordance with google trends, therefore, it is proven the importance of understanding and utilization of SEO (Search Engine Optimized). Meanwhile, the RMOL News Agency social media maintained by RMOL IT division. Specializing in politics, law and security, RMOL uses social media to monitor opinions and statements coming out of official accounts of the political elite, state institutions, political influencers as well as the general public who use social media. RMOL effectively uses Twitter in building media awareness, reaching the number of $95.8 \mathrm{~K}$ followers.

\subsection{Discussion}

Twitter has indulged many researchers because of its' extraordinary ability as a medium of dissemination and information gathering, to explore the relationship between journalism and Twitter using content analysis. Whether consciously or not, journalist also use social media on their daily work, through social media journalist starts finding information sources, publishing information or just having communication [20]. This research failed to prove the hypothesis that there is a reciprocal relationship between online news sites and Twitter, although in 
theory, there should be a tendency of agenda between the two media based on previous research that there is a tendency of agenda between social media and online media [21]-[23].

Research on the online media agenda and social media has a traditional perspective that in the new media era it is possible to create fragmentation in the public because social cohesion is not created through a common ground. The difference in character between conventional mass media and online media raises question whether the agenda setting is still relevant. Social media increases users' participatory on issues they interested in, which could create new questions about who is the gatekeeper in a media. Several studies have been conducted to examine the relevance of agenda setting theory in the convergence era, which concludes that there are still editorial policies in online media despite active participation from media users [24], the use of the internet is also not necessarily eliminating the relevance of agenda setting theory [25], [26].

\section{Conclusion}

Online media (JPNN.com and RMOL.id) getting news not solely from what is viral on social media, even though online media is also unconsciously create the news from viral issues. Their editorial policy to set an issue into the news agenda through a fairly rigorous editorial process, verification and confirmation is still being carried out on news or information circulating in the mainstream media and on social media. From each panel examined, statistically, it is not enough to conclude media agenda setting, this can be influenced by several factors, including the method used, sample characteristics, demographics, problem that examined, including historical factors, and other influences. Demographics of political-focus online media and social media Twitter is different, and the creativity of presidential election hashtag also may affect the study

The results of this study have implications for the basic assumptions of the mass communication theory setting agenda, and can be a new study related to the relevance of the agenda setting in the contemporary media era.

\section{References}

[1] V. Nightingale and I. Webster, "Computer Users As Media Audiences,” Prometheus, vol. 4, no. 1, pp. 128-140, 1986.

[2] K. Saddhono, A. Hasibuan, and M. I. Bakhtiar, "Facebook as A Learning Media in TISOL (Teaching Indonesian to Speakers of Other Languages) Learning to Support the Independency of Foreign Students in Indonesia," J. Phys. Conf. Ser., vol. 1, 2019.

[3] M. McCombs and D. Shaw, "The Agenda-Setting function of mass media," in Agenda Setting: Readings on Media, Public Opinion, and Policymaking, 2016, pp. 17-26.

[4] M. J. Chaffee, Steven H. ; Metzger, "The end of mass communication ?," Mass Commun. Soc., vol. 4, no. 4, pp. 365-379, 2001.

[5] A. Ng Yi Kai, "The relationship between blogs and newspapers in Singapore: an Itermedia agenda-setting study," National University Of Singapore, 2010.

[6] K. D. Sweetser, G. J. Golan, and W. Wanta, "Intermedia agenda setting in television, advertising, and blogs during the 2004 election," Mass Commun. Soc., 2008.

[7] X. Qian, "Inter-media agenda-setting effects among Chinese newspapers, Chinese blogs and the New York Times during coverage of the Beijing 2008 Olympic Games," 2009.

[8] S. Chattopadhyay and M. Greenwood, "A Different Kind of Inter-Media Agenda Setting: How Campaign Ads and Presidential Debates Influenced the Blogosphere in the 2008 U.S. 
Campaign," 2010

[9] Y. Kim, W. J. Gonzenbach, C. J. Vargo, and Y. Kim, "First and second levels of intermedia Agenda setting: Political advertising, newspapers, and twitter during the 2012 U.S. presidential election," Int. J. Commun., vol. 10, pp. 4550-4569, 2016.

[10] E. G. Sikanku, "Intermedia influences among Ghanaian online and print news media: Explicating salience transfer of media agendas," J. Black Stud., 2011.

[11] S. Valenzuela, S. Puente, and P. M. Flores, "Comparing Disaster News on Twitter and Television: an Intermedia Agenda Setting Perspective,” J. Broadcast. Electron. Media, 2017.

[12] M. . Roberts, M; McCombs, "Agenda setting and political advertising: origins of the news agenda," vol. 11, no. 3, pp. 249-262, 1994.

[13] J. . Tedesco, "Issue and Strategy Agenda-Setting in the 2000 Presidential Primaries," Am. Behav. Sci., vol. 44, no. 12, pp. 2048-2067, 2001.

[14] S. W. Dunn, "Candidate and media agenda setting in the 2005 Virginia gubernatorial election," J. Commun., vol. 59, no. 3, pp. 635-652, 2009.

[15] K. D. Sweetser, G. J. Golan, and W. Wanta, "Intermedia agenda setting in television, advertising, and blogs during the 2004 election,” Mass Commun. Soc., vol. 11, no. 2, pp. 197216,2008

[16] M. J. Kushin, "Tweeting The Issues In The Age Of Social Media: Intermedia Agenda Setting Between The New York Times and Twitter," Washington State University, 2010.

[17] F. . Lopez-Escobar, E; Llamas, J.P; McCombs, M.E; Lennon, "Two levels of agenda setting among advertising and news in the 1995 Spanish elections," Polit. Commun., vol. 15, no. 2, pp. 225-238, 1995.

[18] D. . Shadish, W.R; Cook, T.D; Campbell, Experimental and quasi-experimental design for generalized casual influence. Boston: Houghton, Mifflin and Company, 2002.

[19] D. . Rozelle, R.M; Campbell, "More plausible rival hypothesis in the cross-lagged panel correlation technique," Psychol. Bull., vol. 71, no. 1, pp. 74-80, 1969.

[20] S. Suraya, "Journalist Credibility Based on Digital Media Used," ISKI J. Commun., vol. 4, no. 1, pp. 26-34, 2019.

[21] L. Lee, B; Lancendonfer, K; K. J, "Agenda-setting and the internet: the intermedia influence of internet bulletin boards on newspaper coverage of the 2000 general election in South Korea," Asian J. Commun., vol. 15, pp. 57-71, 2005.

[22] T. Roberts, M; Wanta, W; Dzwo, "Agenda setting and issue salience online," Communic. Res., vol. 29 , no. 4, pp. 452-465, 2002.

[23] K. Wallsten, "Agenda Setting and The Blogosphere: An Analysis of The Relationship Between Mainstream Media and Political Blogs," Rev. Policy Res., vol. 24, no. 6, pp. 567-587, 2007.

[24] T. S.L, Althaus; D, "Agenda setting and the 'new' news: pattern of issue importance among readers of the paper and online versions of the New York Times," Community Res., vol. 29, pp. 180-207, 2002.

[25] Y. D, Aikat; J, "News on the web: agenda setting of online news in websites of major newspaper, television, and online news service," Int. Commun. Assoc., 2005.

[26] M. E. Coleman, R; McCombs, "The young and agenda-less ? exploring age-related differences in agenda setting on the youngest generation, baby boomers, and civic generation," Journal. Mass Commun. Quaterly, vol. 84, no. 3, pp. 495-508, 2007 